This item was submitted to Loughborough's Research Repository by the author.

Items in Figshare are protected by copyright, with all rights reserved, unless otherwise indicated.

\title{
Performance and radiation patterns of aesthetic and asymmetric logo-based patch antennas
}

PLEASE CITE THE PUBLISHED VERSION

http://dx.doi.org/10.1080/09205071.2014.893844

PUBLISHER

(c) Taylor \& Francis

VERSION

AM (Accepted Manuscript)

LICENCE

CC BY-NC-ND 4.0

REPOSITORY RECORD

Whittow, W.G., and Jonathan M. Rigelsford. 2019. "Performance and Radiation Patterns of Aesthetic and Asymmetric Logo-based Patch Antennas". figshare. https://hdl.handle.net/2134/14371. 
This item was submitted to Loughborough's Institutional Repository (https://dspace.lboro.ac.uk/) by the author and is made available under the following Creative Commons Licence conditions.

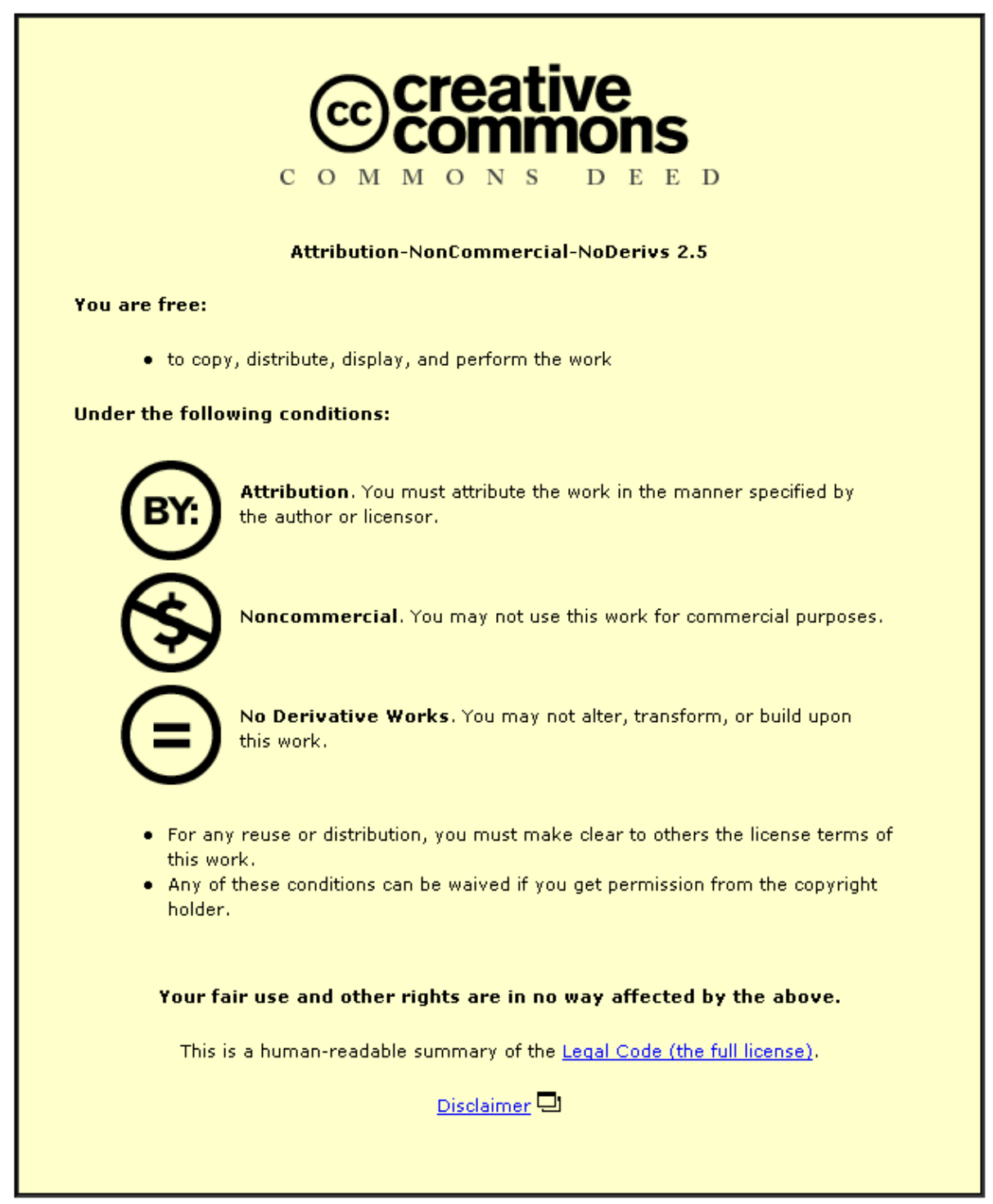

For the full text of this licence, please go to: http://creativecommons.org/licenses/by-nc-nd/2.5/ 


\title{
Performance and Radiation Patterns of Aesthetic and
}

\section{Asymmetric Logo Based Patch Antennas}

\author{
William G Whittow ${ }^{1}$ and Jonathan M. Rigelsford ${ }^{2}$ \\ ${ }^{1}$ School of Electronic, Electrical and Systems Engineering, Loughborough University, Loughborough, \\ LE11 3TU, UK. w.g.whittow@lboro.ac.uk; +44 (0)1509 227105 \\ ${ }^{2}$ Department of Electrical Engineering, University of Sheffield, Sheffield, S1 3JD, UK. \\ j.m.rigelsford@sheffield.ac.uk: +44 (0) 1142225584
}

Final author version

\section{Journal of Electromagnetic Waves and Applications}

Volume 28, Issue 7, pp 848-860, 2014

DOI: $10.1080 / 09205071.2014 .893844$

http://www.tandfonline.com/doi/full/10.1080/09205071.2014.893844 


\title{
Performance and Radiation Patterns of Aesthetic and Asymmetric Logo Based Patch Antennas
}

\author{
William G Whittow ${ }^{1}$ and Jonathan M. Rigelsford ${ }^{2}$ \\ ${ }^{1}$ School of Electronic, Electrical and Systems Engineering, Loughborough University, Loughborough, \\ LE11 3TU, UK. w.g.whittow@lboro.ac.uk; +44 (0)1509 227105 \\ ${ }^{2}$ Department of Electrical Engineering, University of Sheffield, Sheffield, S1 3JD, UK. \\ j.m.rigelsford@sheffield.ac.uk: +44 (0) 1142225584
}

\begin{abstract}
This paper investigates microstrip patch antennas designed using aesthetic and asymmetrical logo based shapes. A range of shapes has been considered and analyzed using electromagnetic simulations and measurements. Particular attention has been given to the radiation patterns of these asymmetric antennas.
\end{abstract}

\section{Introduction}

Antennas and wireless connectivity are essential to our everyday activity. However, antennas are generally functional objects that need to be miniaturised and hidden to avoid hindering the aesthetics of the product in which it is incorporated into. This means compromising the antenna in terms of size which limits the inherent efficiency and bandwidth due to the Wheeler-Chu limits [1], [2]. Surrounding materials and non-ideal placement also compromise electromagnetic performance. Conversely, if the antenna was an aesthetic shape, for example a flower, a smiley face or even a company logo, these restrictions could be negated. This concept lends itself particularly to wearable technology where the antenna can be integrated into the clothing and hence the size restrictions are relaxed [3]-[6]. Automated and computer controlled manufacturing techniques include embroidering antennas using conducting threads [7] or inkjet printing [8] can easily create complex shapes. The integration of antennas into clothing means that they cannot be left behind, dropped, lost and they do not need to be hand-held. Potentially, aesthetic antennas could initiate consumer and company interest in main stream products. Another potential application of aesthetic antennas is Radiofrequency Identification (RFID) which is a rapidly growing industry to track parts and products including library books, orders and contactless payments as well as people and is expected to be worth $£ 11.7 \mathrm{~B}$ by 2017 [9].

This new attitude to antenna design could be particularly attractive to companies as it reinforces technology and functionality with a recognised brand to create a unique product. In many cases, it will be preferable to have a stylish aesthetic antenna that feels like part of the clothing or product rather than trying to hide or cover a conventional rectangular shape. The technology itself would also be protected by copyright and registered design rights.

Microstrip patch antennas are popular due to their low profile; ease of construction and the isolation from 
other objects due to the ground plane [10], [11]. Different geometries have been considered including square, triangular rectangular, circular, elliptical, slots and parasitic elements [12], [13]. However, these shapes were optimised for their electromagnetic performance and the aesthetic aspects were not considered.

Recently, symmetric or quasi-symmetric logo-based monopole and dipole antennas have recently been considered. These antennas would be detuned in the presence of nearby metal objects due to the lack of ground plane. They also require an element of symmetry in the design. Logo based microstrip patch antennas do not have this disadvantage. Furthermore, microstrip patch antennas can consist of asymmetric shapes. A short letters paper about a single logo patch antenna has been published but the radiation patterns were not considered [14]. A review of the literature indicates that logo-based microstrip patch antennas have received little attention and the radiation patterns of these asymmetric shapes have not been previously presented.

In [15], a logo design was placed inside a circle but it was predominantly the circle which acted as the antenna and not the logo itself. In [16] and [17] the impedance match of a text-based logo dipole antenna was changed by modifying the shape of connected letters. A text-based dipole RFID antenna has been created by physically connecting individual letters [18] and a text based dipole antenna with joined up letters has been examined [19]. A symmetric variant of a ring based monopole has been considered for wideband applications [20].

A symmetric RFID dipole based antenna has been fabricated using conducted thread while the asymmetric logo based section was made using non-conducting thread [21]. A simple symmetric modified dipole antenna printed on a paper substrate was implemented into running footwear to act as an RFID device [22]. A symmetric UHF RFID dipole antenna of an arbitrary shape has been fabricated using screen printing techniques [23].

A PIFA based design was considered which resembled the U shape of the University of Utah logo for vehicular applications [24]. The same paper considered an array of patch antennas to spell the word 'UTAH' where each letter was tuned to $2.45 \mathrm{GHz}$ [24]. This paper did not give details of the antenna performance but concentrated on the simulated channel capacity.

A rectangular patch antenna with a W-based logo slot has been considered [25]. Note, in that paper, the slot was a logo shape but the patch was rectangular. A microstrip meander line with a $3 / 4$ circle has been investigated - however the current distribution suggests that the $3 / 4$ circle is not relevant to the function of the antenna [26].

This paper will examine the performance of several logo shaped patch antennas with increasingly complex designs. Section 2 describes the geometry of the set of three antennas. Section 3 presents simulated predictions for the three antenna designs described in Section 2. Measured reflection coefficient and radiation patterns of the antennas are given in Section 4 and compared to those obtained via simulation. Section 5 provides an analysis of the Logo antenna design and demonstrates how minor modifications to the shape can improve its performance. Conclusions will be drawn in Section 6.

\section{Geometry}

In this paper, three diverse antenna geometries with increasing complexity were used for the radiating elements of microstrip patch antennas: i) a representative asymmetric logo Circle-shape with a concave section removed; ii) a real logo with angular, curved and a disconnected section- the Loughborough University (LU) logo (with prior permission granted) - "LU" and iii) a complex shape that contains a series of letters, which spelt out the word 'Logo' with additional disconnected parts. These three geometries are shown in Figure 1. The optimum feed position was found by optimizing the simulations. The feed positions for all three antennas are shown in Figure 1. 
To allow a fair comparison, the longest side of the radiating element of the antennas was $60 \mathrm{~mm}$ wide. The ground plane was $120 \times 120 \mathrm{~mm}$. Note that simulations have verified that the antennas can be linearly scaled to tune to a particular frequency.

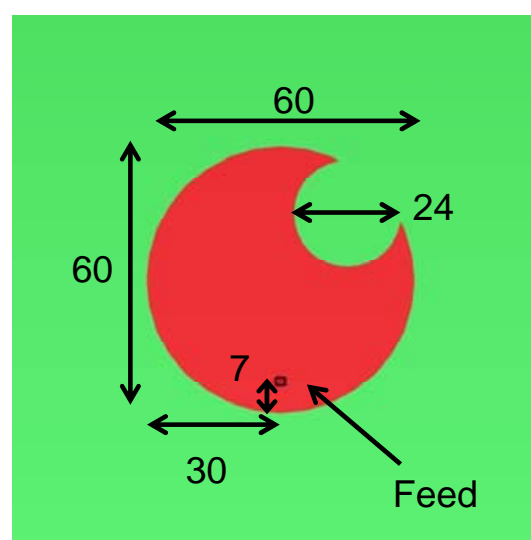

(a)

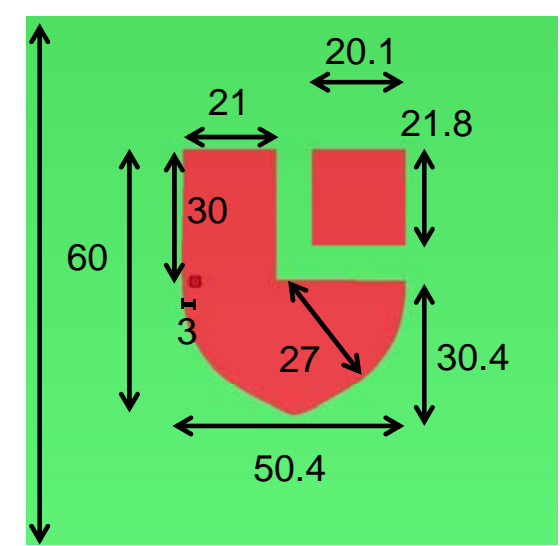

(b)

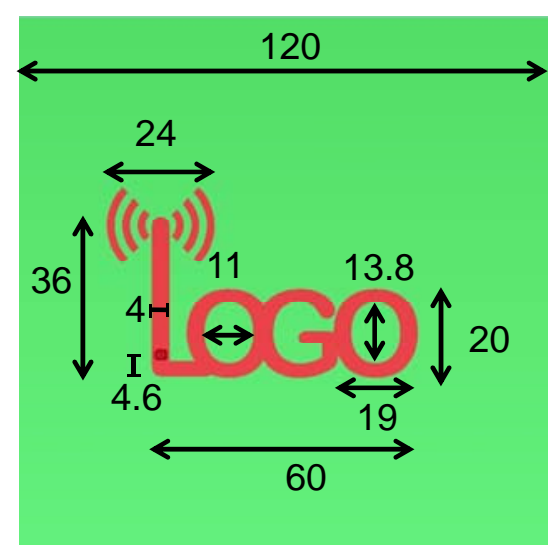

(c)

Figure 1. Geometry of the three patch antennas: (a) Circle-shape; (b) LU Shield and (c) bespoke 'Logo'. All distances are in $\mathrm{mm}$

\section{Antenna analysis and simulated results}

The three antenna designs presented in Figure 1 were simulated using EMPIRE XCcel finite-difference time-domain (FDTD) commercial software (www.empire.de). The software used a Gaussian pulse as the excitation covering the frequency range 0 to $5 \mathrm{GHz}$. Perfectly matched layer absorbing boundary conditions, 8 cells thick, were used on all six boundaries. The simulations were run until the excitation had decayed to $50 \mathrm{~dB}$ to ensure the results were fully converged. The cell size and related time step were determined by the automatic meshing using at least 20 cells per wavelength. The software's "perfect geometry approximation" algorithm was implemented to minimize the stair-casing errors for the curved sections of the antennas. The substrate in this paper was chosen as FR4 for manufacturing convenience $\left(\varepsilon_{\mathrm{r}}=4.5\right.$; $\left.\tan \delta=0.02\right)$ having a thickness of $1.6 \mathrm{~mm}$. This paper investigates the behavior of logo based antennas and the results can be extrapolated to other materials.

\subsection{Reflection coefficient}

Simulated reflection coefficient results for the: (a) the Circle-shape; (b) the LU shield and (c) the 'Logo' antennas are shown in Figure 2. It can be seen that each design has at least three nulls in the reflection coefficient (S11) results between 1 and $5 \mathrm{GHz}$. This suggests that each antenna could potentially be used for multiband applications. The Circle-shape antenna has narrow-band nulls exceeding $-10 \mathrm{~dB}$ at 1.15, 1.53, 2.08; 3.07, 3.61 and 4.54GHz. The LU-Shield antenna has narrow-band nulls exceeding -10dB at 1.06, 1.85 and 2.47 with a broader bandwidth null occurring at $3.24 \mathrm{GHz}$. The 'Logo' antenna has three narrow band nulls exceeding $-10 \mathrm{~dB}$ at 1.14, 2.51 and 4.60GHz. The surface currents shown in Figure 3 indicate the behavior of the three antennas at the first two resonance frequencies. 


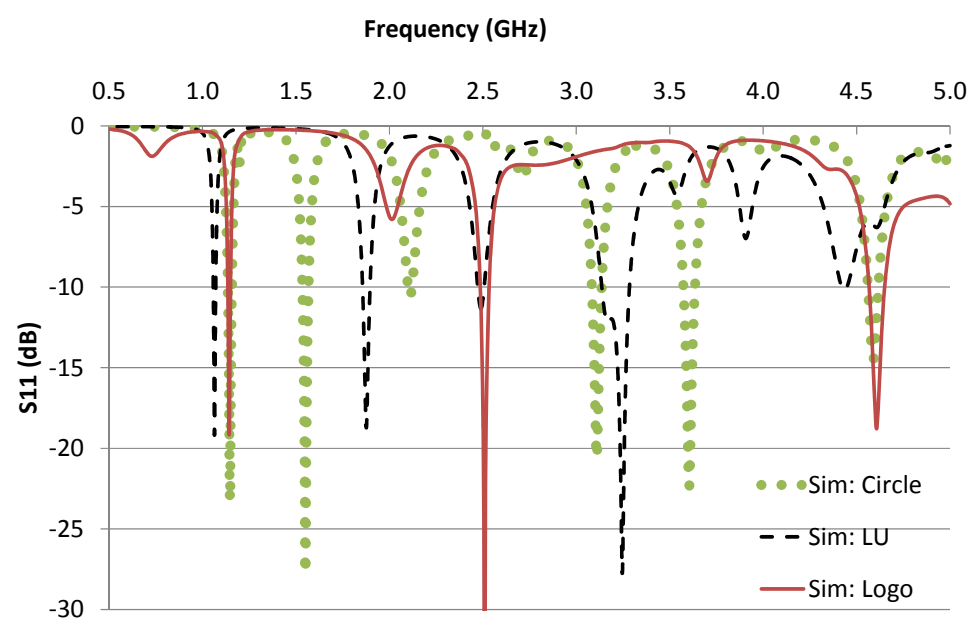

Figure 2. Simulated reflection coefficient results

(a)

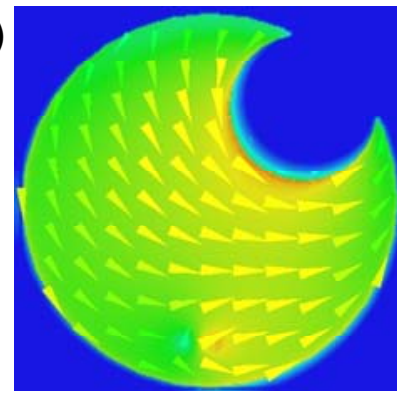

(b)

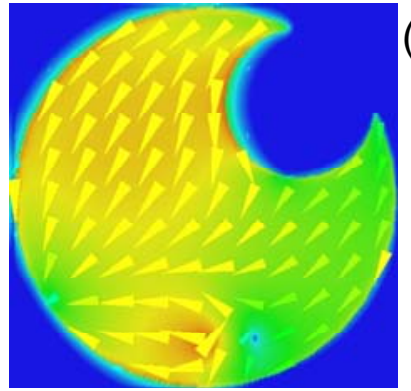

(c)

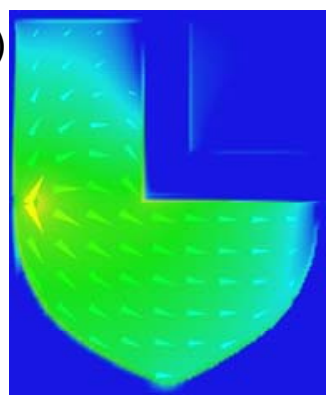

(d)

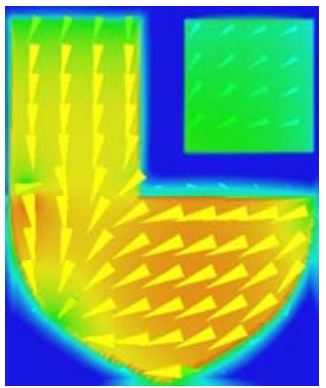

(e)

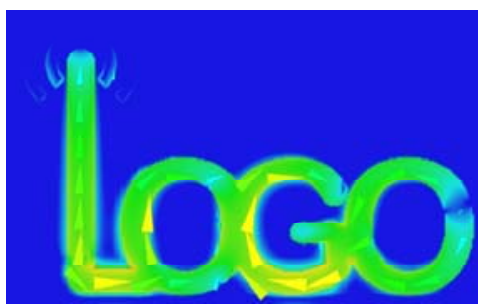

(f)

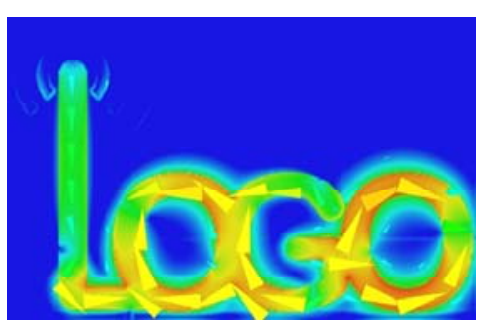

Figure 3. Surface currents: (a) Circle-shape at 1.15GHz; (b) Circle-shape at 1.55GHz; (c) LU Shield at 1.06GHz; (d) LU Shield at $1.88 \mathrm{GHz}$; (e) 'Logo' at $1.14 \mathrm{GHz}$ and (f) 'Logo' at $2.50 \mathrm{GHz}$. Arrows are included to show the current direction

\subsection{Gain and efficiency}

Results of the simulated antennas at each of the different frequencies are presented in Table 1. For each of the three antenna designs, the table presents the frequency and depth of the nulls from the reflection coefficient results, the $-10 \mathrm{~dB}$ bandwidth, the fractional bandwidth, gain and antenna efficiency. Results for a standard rectangular patch measuring $50 \times 60 \mathrm{~mm}$ are included for comparison. Table 1 indicates that some of the resonant frequencies are not radiating modes. This can be clearly seen for the first two frequencies for the 'Logo' antenna. The rectangular patch antenna has an efficiency of approximately $35 \%$ due to the lossy FR 4 substrate. Therefore, 
all results should be compared to the rectangular patch antenna and could be improved by using a low loss substrate. When the loss tangent of the substrate was reduced to 0.0037 , the simulated radiation efficiencies at the first three resonances of the rectangular patch antenna were 71.6; 68.5 and 38.4\%, respectively. Note, for the low loss substrate simulations, the radiation efficiency was used instead of the total efficiency as a fairer comparison as the matching of the antenna changed with the low loss substrate. The radiation efficiencies of the Circle-shape antenna with the low loss substrate were: $36.0 ; 62.5 ; 50.8$ and $45.5 \%$. Therefore, by reducing the losses from the substrate - the efficiency can be restored to acceptable levels.

\subsection{Radiation patterns}

As the patch antennas in this paper are geometrically asymmetric, it is therefore interesting to examine the radiation patterns. Figures 3-5 show the simulated co-polar radiation pattern results for the two principle planes. The values are not normalized to show the relative differences in antenna gain.
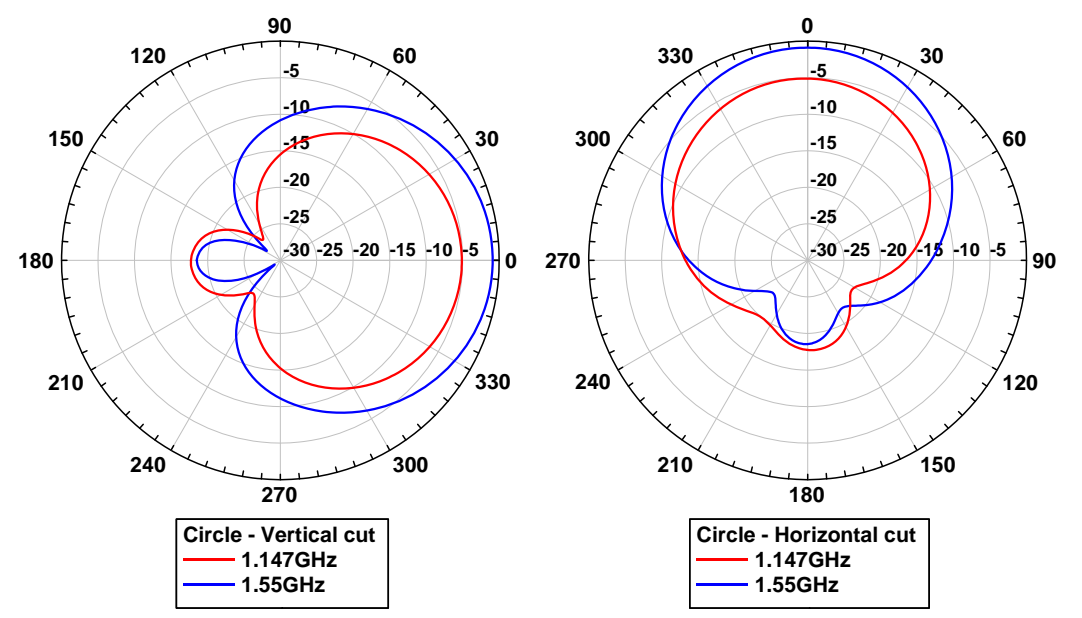

Figure 4. Simulated co-polar radiation patterns for the Circle-shape antenna
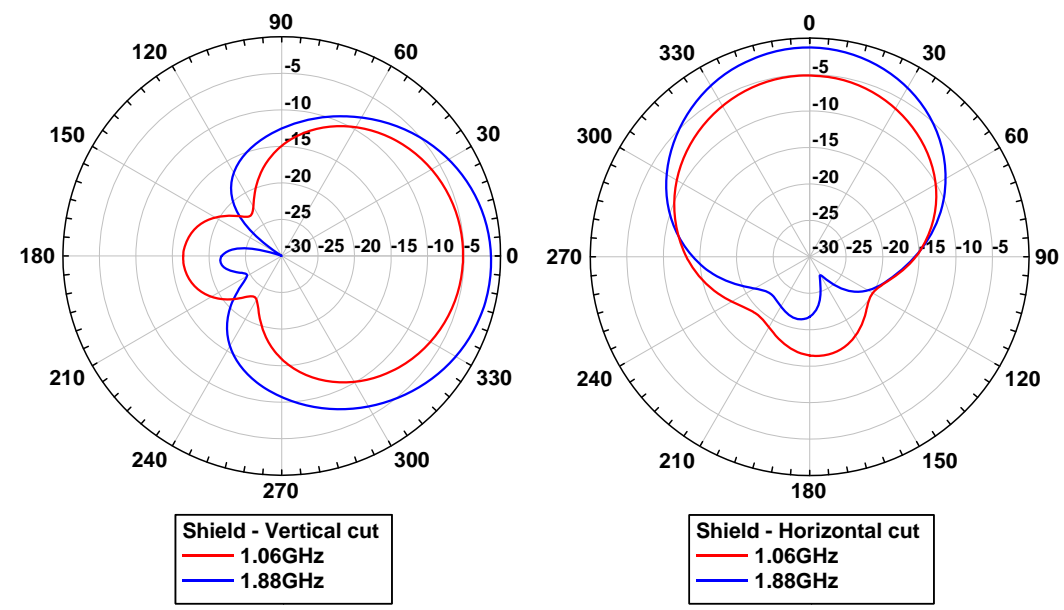

Figure 5. Simulated co-polar radiation patterns for the LU Shield Antenna 

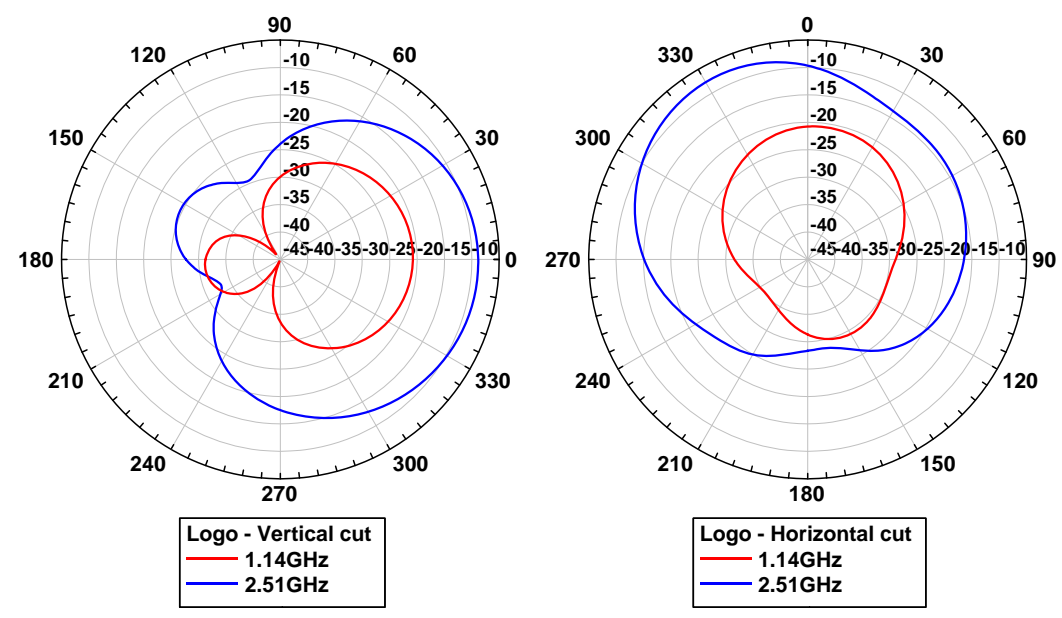

Figure 6. Simulated co-polar radiation patterns for the 'Logo' antenna

\section{Measurements and results}

Prototypes of the Circle-shape, LU Shield and 'Logo' were etched on FR4 substrates for experimental validation of the simulated predictions, as shown in Figure 7. S-parameter measurements were performed on the antenna using an Agilent E8364B PNA vector network analyser. A comparison between the simulated and measured reflection coefficient (S11) results is presented in Figure 8. It can be seen that there is excellent agreement between the measured and predicted results for all three antenna designs.
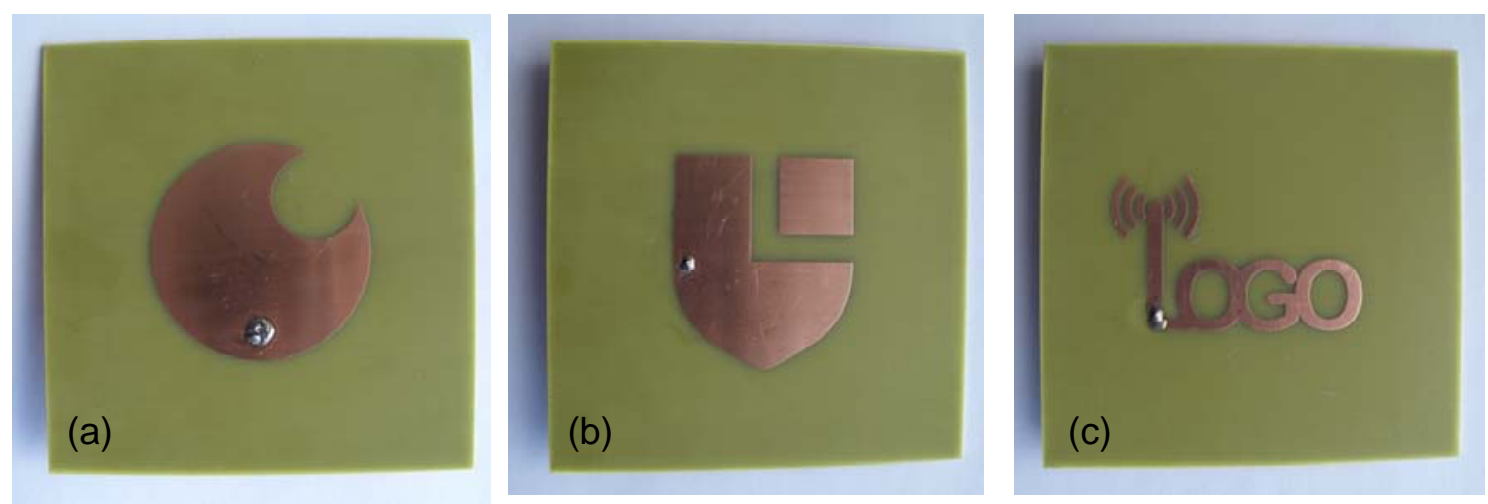

Figure 7. Fabricated antennas: (a) Circle-shape; (b) LU Shield and (c) 'Logo' antenna

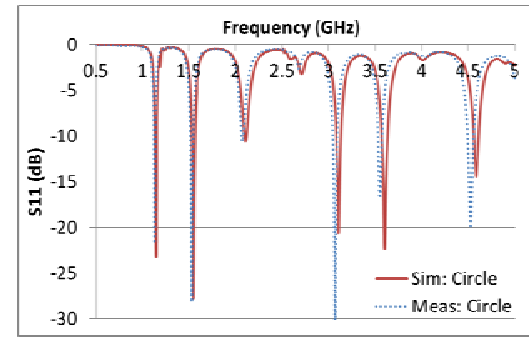

(a)

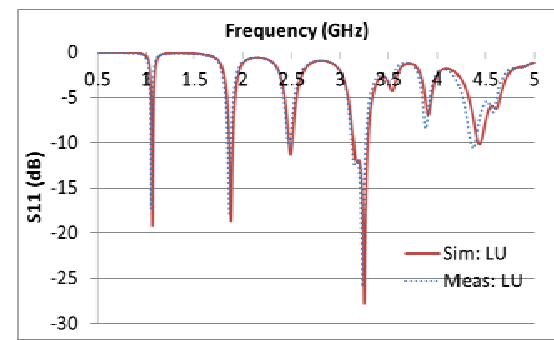

(b)

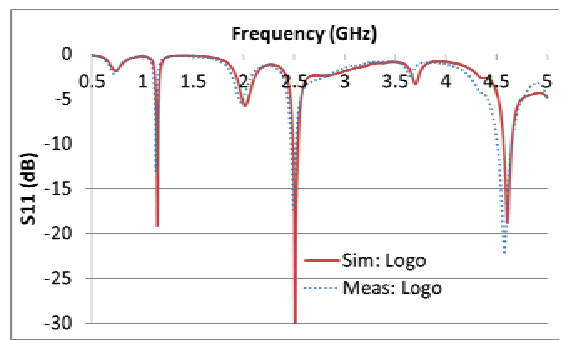

(c)

Figure 8. The simulated and measured S11 results: (a) the Circle-shape; (b) the LU Shield and (c) 'Logo' 
Experimental antenna radiation patterns were obtained using a NSI $800 \mathrm{~F}-10$ far-field measurement system within an anechoic chamber located at the University of Sheffield, lined with 12" and 36" pyramidal absorber. The antennas under test were carefully aligned and two radiation patterns performed for each cut, with the antenna being rotated by $180^{\circ}$ for the second pattern. In post processing for each cut, the two patterns were averaged after the data for second pattern has been inverted again. This is a common technique which is used to eliminate any "squint" which may result from the measurement environment and to reduce environmental noise. This technique results in very smooth patterns which are less susceptible to antenna range measurement errors. Radiation patterns showing both vertical and horizontal cuts of the three antenna designs can be seen in Figures 8-10. Results have not been normalised to show the differences in gain (and therefore an indication of relative efficiency) and the absolute numbers are 'raw' and have not been adjusted for range path loss or the gain of the transmitting antenna.
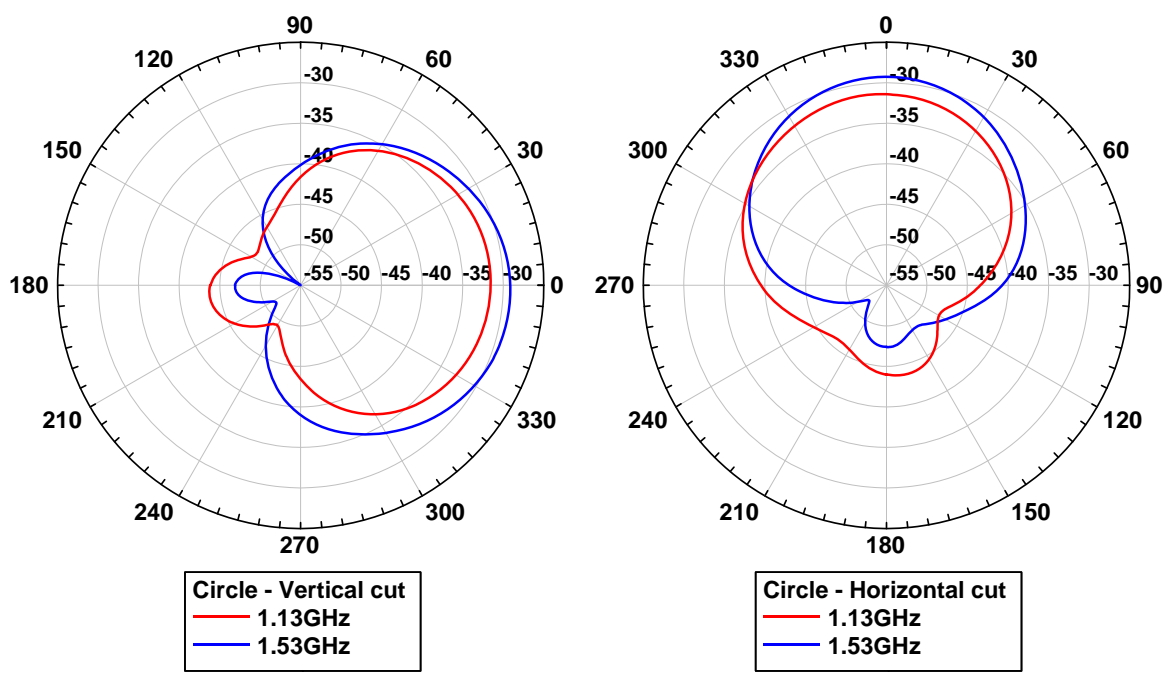

Figure 9. Measured co-polar radiation patterns for the Circle-shape antenna
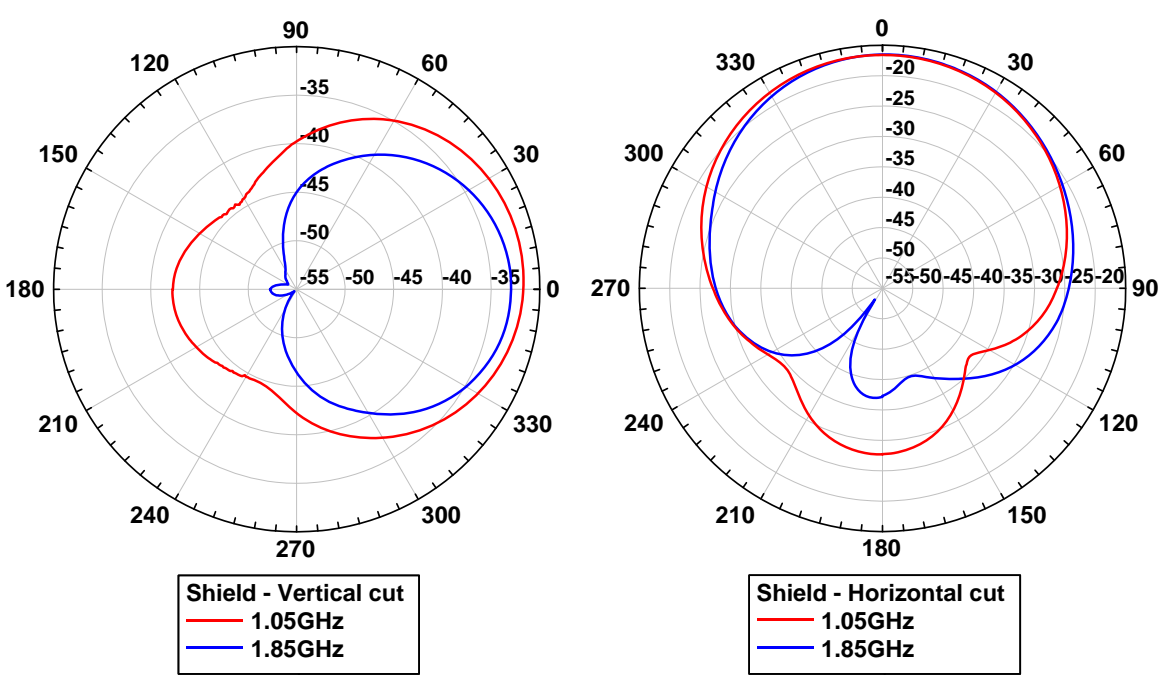

Figure 10. Measured co-polar radiation patterns for the LU Shield antenna 

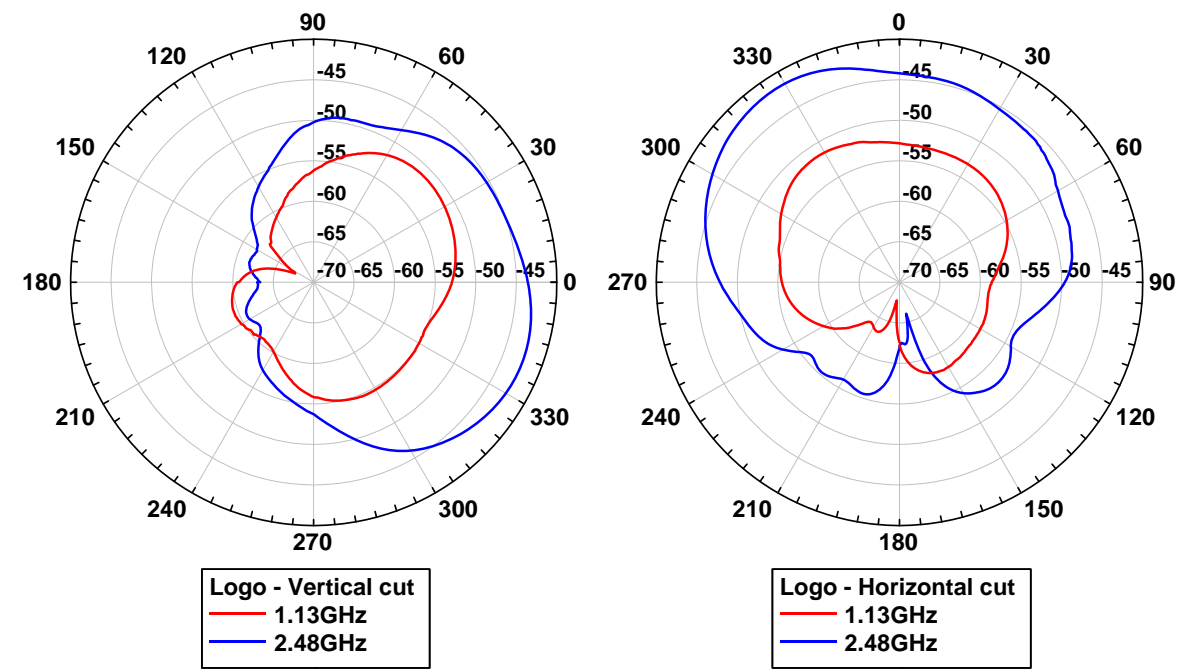

Figure 11. Measured co-polar radiation patterns for the 'Logo' antenna

For clarity, a comparison between the simulated and measured co-polar radiation patterns is given in Figure 12. It can be seen that there is excellent agreement between the measured and predicted radiation patterns for both the Circle-shape (Figure 12a) and LU Shield (Figure 12b) antennas. Due to the poor radiating efficiency of the 'Logo' antenna (Figure 12c) at the first two resonant frequencies, the agreement between the measured and predicted radiation patterns was not so clear. This can be partially explained by the fact that the received power is $20-30 \mathrm{~dB}$ lower than that of the other two designs.
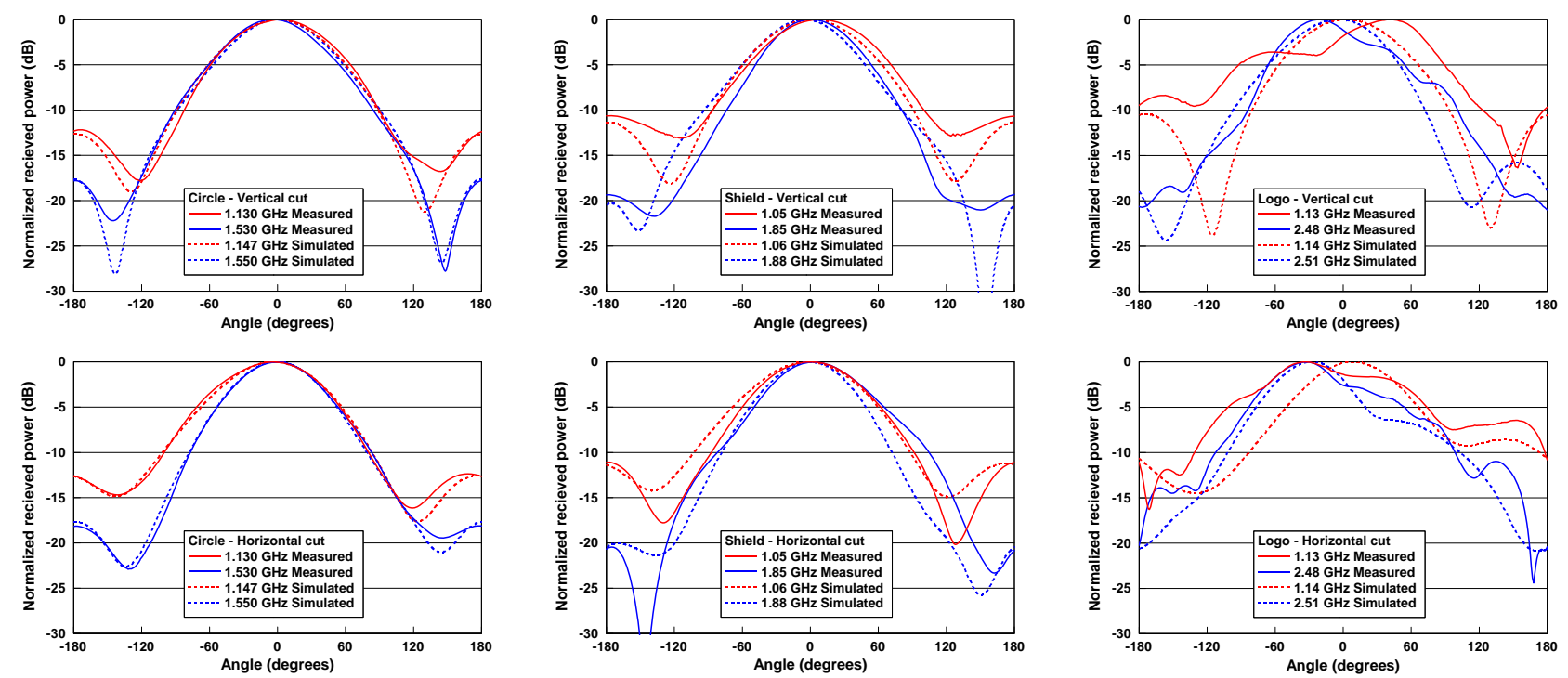

(a)

(b)

(c)

Figure 12. Comparison between measured and simulated radiation patterns for a) the Circle-shape; (b) the LU Shield and (c) the 'Logo' antenna 


\section{5. 'Logo' shape analysis}

The logo based antennas in Table 1 exhibited lower efficiencies than the standard rectangular antenna. Therefore, the aesthetic shape can come at the expense of reduced efficiency. The efficiency of the 'Logo' antenna was particularly low. Surface currents shown in Figure 14, indicate that the currents on different sections of the O's were in opposite directions. To alter the surface currents and hence the performance, a range of 'Logo' shape variants were simulated including those shown in Figure 13 and the results are shown in Table 2. Figure 13 (b) consists of solid O's. This increased the efficiency to $14.1 \%$ at $2.09 \mathrm{GHz}$ and $22.2 \%$ at $3.02 \mathrm{GHz}$. Adding small holes in the O's, see Figure 13 (c), behaved like Figure 13 (b). In Figure 13 (d) a small piece of conductor was placed between the $\mathrm{G}$ and the $2^{\text {nd }} \mathrm{O}$ to change the current path. This had minimal effect on the aesthetic design but changed the behavior of the antenna and increased the efficiency to $29.7 \%$ at $2.98 \mathrm{GHz}$. This efficiency is comparable to the efficiency of the rectangular patch antenna on the same lossy FR4 substrate. Cutting slots in the design as shown in Figure 13 (e) and (f) did not improve the gain but altered the frequencies.
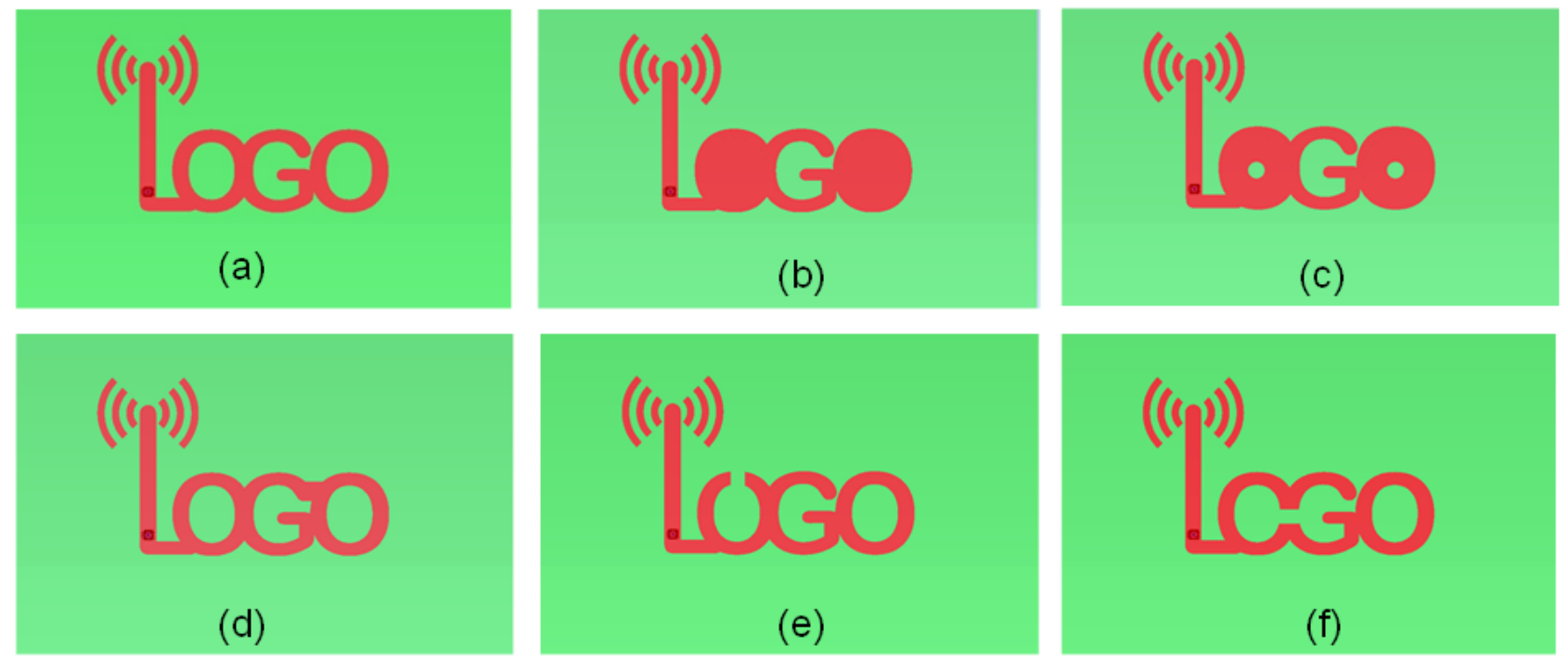

Figure 13. 'Logo' antenna shape variants: (a) original design; (b) solid O's; (c) small holes in O's; (d) G connected to $2^{\text {nd }} \mathrm{O}$; (e) slot in first $\mathrm{O}$; (f) slot between first $\mathrm{O}$ and $\mathrm{G}$ 


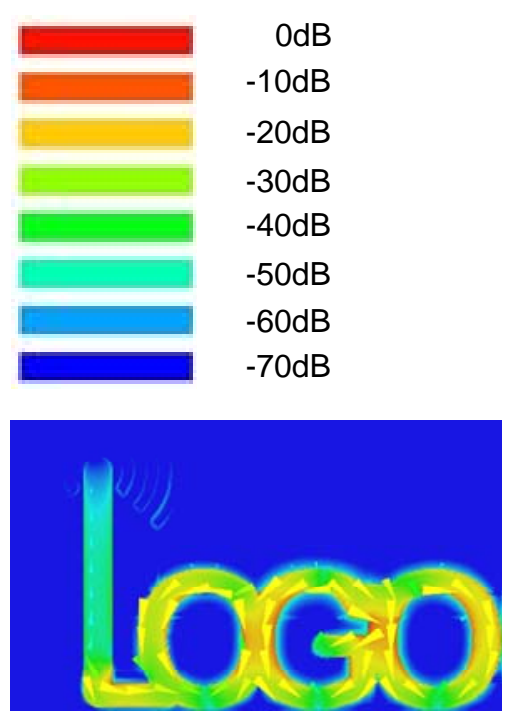

(c)

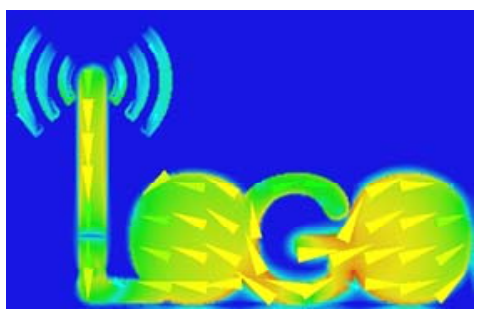

(a)

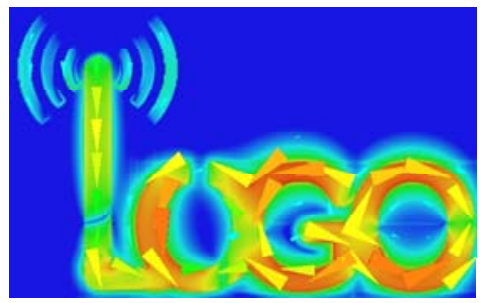

(d)

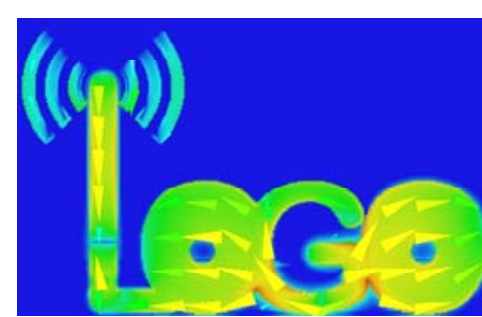

(b)

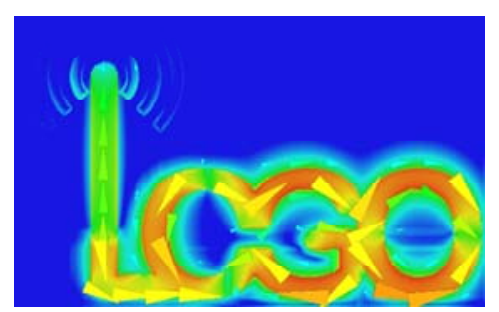

(e)

Figure 14. Surface currents on 'Logo' variants at the $3 \mathrm{GHz}$ resonance frequency: (a) solid O's; (b) small holes in $\mathrm{O}$ 's; (c) $\mathrm{G}$ connected to $2^{\text {nd }} \mathrm{O}$; (d) slot in first $\mathrm{O}$; (e) slot between first $\mathrm{O}$ and $\mathrm{G}$. The arrows indicate the direction

\section{Conclusions}

This paper has considered logo inspired microstrip patch antennas. This has implications for applications where it is desirable to enhance the aesthetic appeal or marketing aspects of antennas. By changing the trend from hiding antennas to making them part of the product design, the size and location constraints can be relaxed which can in turn improve the performance. This could be particularly relevant to the emerging field of wearable applications where a textile antenna does not have to be constrained by the size of the electronics. One of the key challenges to integrate wearable technology into the mainstream is fashion and social acceptance. Therefore, logo based antennas will be attractive to consumers and also to companies who wish to differentiate their products, avoid counterfeit products and associate their product with both technology and design.

In this paper, a range of shapes have been simulated and measured. Different shapes can function as antennas and they can be scaled to the required frequency. Changing the outline of the shape, extends the current path and reduces the resonant frequency, however, the efficiency and gain are reduced. Disconnected parts of the shape generally do not affect the lower frequencies but the coupling can increase at higher frequencies. Certain shapes can be well matched but do not radiate effectively at lower frequencies but these shapes can become reasonable radiators at higher frequencies. Some shapes and logos will naturally make good antenna designs and others will not. The asymmetric designs lead to asymmetric but functional radiation patterns.

The efficiency can be increased by making minor changes to the design to alter the current paths. If the required shape is a company brand or logo, there may be limitations to changing the design. However, if the shape is a general aesthetic shape - there is further scope for modifications.

\section{Acknowledgements}

The authors would like to thank the Dr. Richard Bibb for his assistance creating the STL files and Loughborough University (who own the copyright) for allowing their Shield to be used in this paper. 


\section{References}

[1] H. A. Wheeler, "Fundamental Limitations of Small Antennas," Proc. IRE, vol. 35, no. 12, pp. 1479-1484, 1947.

[2] L. J. Chu, "Physical limitations on omni-directional antennas," J. Appl. Physics, vol. 19, no. Dec, pp. 1369-1393, 1948.

[3] P. S. Hall and Y. Hao, Antennas and Propagation for Body-Centric Wireless Communications. London, UK: Artech House, 2012.

[4] S. L. Cotton and W. G. Scanlon, "Channel Characterization for Single- and Multiple-Antenna Wearable Systems Used for Indoor Body-to-Body Communications," IEEE Trans. Antennas Propag., vol. 57, no. 4, pp. 980-990, Apr. 2009.

[5] Q. Bai and R. Langley, "Crumpling of PIFA Textile Antenna,” IEEE Trans. Antennas Propag., vol. 60, no. 1, pp. 63-70, 2012.

[6] B. Sanz-Izquierdo, J. C. Batchelor, and M. I. Sobhy, "Button antenna on textiles for wireless local area network on body applications," Microwaves, Antennas Propagation, IET, vol. 4, no. 11, pp. 1980-1987, 2010.

[7] R. D. Seager, S. Zhang, A. Chauraya, W. G. Whittow, J. C. Vardaxoglou, T. Acti, and T. Dias, "Effect of the Fabrication Parameters on the Performance of Embroidered Antennas," IET Microwaves, Antennas Propag., vol. 7 , no. 14, pp. 1174-1181, 2013.

[8] A. Chauraya, W. G. Whittow, J. C. Vardaxoglou, L. Yi, R. Torah, K. Yang, S. Beeby, and J. Tudor, "Inkjet Printed Dipole Antennas on Textiles for Wearable Communications," IET Microwaves, Antennas Propag., vol. 7, no. 9, pp. $760-767,2013$.

[9] C. Turcu, Current Trends and Challenges in RFID. Intech, 2011.

[10] J. R. James and P. S. Hall, Handbook of Microstrip Antennas. IET, 1989.

[11] J. R. James, P. S. Hall, and C. Wood, Microstrip Antenna Theory and Design. Peter Peregrinus Ltd, 1986.

[12] K. M. Lee, K. F, Luk, Microstrip patch antennas. Imperial College Press, 2011.

[13] D. Guha and Y. Antar, Microstrip and Printed Antennas: New Trends, Techniques and Applications. Wiley, 2010.

[14] W. G. Whittow, “Antenna Emblems Reshaped as Icons and Aesthetic Logos (AERIAL),” Microw. Opt. Technol. Lett., vol. 55, no. 8, pp. 1711-1714, 2013.

[15] M. S. Mahmud and S. Dey, "Design, performance and implementation of UWB wearable logo textile antenna," in International Symposium on Antenna Technology and Applied Electromagnetics, 2012.

[16] K. Elmahgoub, T. Elsherbeni, F. Yang, A. Z. Elsherbeni, and L. Ukkonen, "Logo-Antenna Based RFID Tags for Advertising Application,” ACES J., vol. 25, no. 3, pp. 174-181, 2010.

[17] W. C. Weng and C. L. Hung, "Design and optimization of a logo-type antenna for mulitband applications," Prog. Electromagn. Res., vol. 123, pp. 159-174, 2012.

[18] M. Keskilammi and M. Kivikoski, "Using text as a meander line for RFID transponder antennas," IEEE Antennas Wirel. Propag. Lett., vol. 3, no. 1, pp. 372-374, Dec. 2004.

[19] C. Huang, Y. Lin, and M. Kuo, "Design of Logo-Based Tag Antennas of RFID Applications," in 2008 International Symposium on Antennas and Propagation, 2008.

[20] M. R. Aghda and M. R. B. Kamarudin, "UTM-logo wideband printed monopole antenna surrounded with circular ring patch,” Prog. Electromagn. Res. C, vol. 15, no. July, pp. 157-164, 2010.

[21] J. Choi, Y. Kim, K. Lee, and Y. Chung, "Various Wearable Embroidery RFID Tag Antenna Using Electro-Thread," in IEEE Antennas and Propagation Society International Symposium (AP-S 2008), 2008.

[22] G. Orecchini, L. Yang, M. M. Tentzeris, L. Roselli, and T. Instruments, "Wearable battery-free active paper printed RFID tag with human-energy scavenger," in IEEE International Microwave Symposium Digest (MTT), 2011. 
[23] T. Elsherbeni, K. Elmahgoub, L. Sydänheimo, L. Ukkonen, A. Elsherbeni, and F. Yang, "Laboratory Scale Fabrication Techniques for Passive UHF RFID Tags," in IEEE International SymposiumAntennas and Propagation Society (APSURSI), 2010.

[24] P. R. S. Ananthanarayanan and C. M. Furse, “Antenna optimization for vehicular environments," 2011 IEEE Int. Symp. Antennas Propag., pp. 2898-2901, Jul. 2011.

[25] Y. L. Chow and C. W. Fung, "The City University Logo Patch Antenna," in Asia-Pacific Microwave Conference Proceedings (APMC '97), 1997, no. 1, pp. $229-232$.

[26] D. Misman, M. Z. A. A. Aziz, M. N. Husain, P. J. Soh, and R. B. Ahmad, "Design and Analysis of an UTeM Antenna," in 2010 Proceedings of the Fourth European Conference on Antennas and Propagation (EuCAP), 2010, no. 1752, pp. 94-97. 
Table 1. Simulated antenna results of a range of logo based shapes on lossy FR4 substrates

\begin{tabular}{|c|c|c|c|c|c|c|}
\hline Antenna & $\begin{array}{c}\text { Frequency } \\
(\mathrm{GHz})\end{array}$ & $\begin{array}{c}\text { Reflection } \\
\text { Coefficient } \\
\text { (dB) } \\
\end{array}$ & $\begin{array}{c}\text {-10dB } \\
\text { bandwidth } \\
\text { (MHz) }\end{array}$ & $\begin{array}{c}\text { Fractional } \\
\text { bandwidth } \\
(\%)\end{array}$ & $\begin{array}{l}\text { Gain } \\
\text { (dBi) }\end{array}$ & $\begin{array}{c}\text { Antenna } \\
\text { Efficiency } \\
(\%) \\
\end{array}$ \\
\hline \multirow{3}{*}{$\begin{array}{c}50 \times 60 \mathrm{~mm} \\
\text { Rectangle }\end{array}$} & 1.39 & -27.3 & 28 & 2.0 & 2.26 & 34.7 \\
\hline & 2.35 & -30.2 & 22 & 0.9 & 2.74 & 30.8 \\
\hline & 2.79 & -15.4 & 45 & 1.6 & -2.68 & 11.4 \\
\hline \multirow{4}{*}{ Circle-shape } & 1.15 & -22.4 & 22 & 1.9 & -2.29 & 13.5 \\
\hline & 1.55 & -27.7 & 33 & 2.1 & 2.03 & 31.9 \\
\hline & 2.11 & -10.5 & 22 & 1.0 & -0.59 & 20.7 \\
\hline & 3.11 & -20.4 & 53 & 1.7 & 0.37 & 18.8 \\
\hline \multirow{4}{*}{ LU Shield } & 1.06 & -19.2 & 14 & 1.3 & -3.11 & 11.1 \\
\hline & 1.88 & -18.6 & 34 & 1.8 & 2.47 & 33.9 \\
\hline & 2.49 & -11.3 & 34 & 1.4 & 1.50 & 26.9 \\
\hline & 3.25 & -27.6 & 148 & 4.6 & 1.85 & 34.0 \\
\hline \multirow{4}{*}{ 'Logo' } & 0.74 & -2.0 & - & - & -20.87 & 0.3 \\
\hline & 1.14 & -19.1 & 15 & 1.3 & -20.33 & 0.3 \\
\hline & 2.02 & -6.0 & - & - & -3.04 & 9.6 \\
\hline & 2.50 & -40.2 & 47 & 1.9 & -3.01 & 11.1 \\
\hline
\end{tabular}


Table 2. Simulated antenna results of 'Logo' antenna variants on lossy FR4 substrates

\begin{tabular}{|c|c|c|c|c|c|c|}
\hline 'Logo' variant & $\begin{array}{c}\text { Frequency } \\
\text { (GHz) }\end{array}$ & S11 (dB) & $\begin{array}{c}-10 \mathrm{~dB} \\
\text { bandwidth } \\
(\mathrm{MHz})\end{array}$ & $\begin{array}{c}\text { Fractional } \\
\text { bandwidth } \\
(\%)\end{array}$ & $\begin{array}{l}\text { Gain } \\
\text { (dBi) }\end{array}$ & $\begin{array}{c}\text { Efficiency } \\
(\%)\end{array}$ \\
\hline \multirow{2}{*}{$\begin{array}{c}\text { 'Logo' } \\
\text { (Figure 13a) }\end{array}$} & 2.02 & -6.0 & - & - & -3.04 & 9.6 \\
\hline & 2.50 & -40.2 & 47 & 1.9 & -3.01 & 11.1 \\
\hline \multirow{2}{*}{$\begin{array}{c}\text { Solid O’s } \\
\text { (Figure 13b) }\end{array}$} & 2.09 & -12.0 & 30 & 1.4 & -1.35 & 14.1 \\
\hline & 3.02 & -7.1 & - & - & 1.06 & 22.2 \\
\hline \multirow{2}{*}{$\begin{array}{l}\text { Small holes in O's } \\
\text { (Figure } 13 c \text { ) }\end{array}$} & 2.09 & -11.4 & 28 & 1.3 & -1.35 & 14.1 \\
\hline & 3.02 & -7.8 & - & - & 0.95 & 22.9 \\
\hline \multirow{2}{*}{$\begin{array}{c}2^{\text {nd }} \text { O connected to } G \\
\text { (Figure } 13 d)\end{array}$} & 1.47 & -9.9 & - & - & -7.61 & 4.1 \\
\hline & 2.98 & -16.2 & $85 *$ & 2.9 & 1.83 & 29.7 \\
\hline \multirow{2}{*}{$\begin{array}{l}\text { Slot in first } O \\
\text { (Figure } 13 e \text { ) }\end{array}$} & 1.56 & -29.1 & 24 & 1.5 & -9.90 & 2.3 \\
\hline & 2.94 & -14.5 & 36 & 1.2 & -5.54 & 6.8 \\
\hline \multirow{3}{*}{$\begin{array}{c}\text { Slot between 1st } O \& \\
G \\
\text { (Figure 13f) }\end{array}$} & 1.65 & -6.7 & - & - & -5.59 & 5.8 \\
\hline & 2.36 & -15.3 & 39 & 1.7 & -5.48 & 5.4 \\
\hline & 2.89 & -17.6 & 73 & 2.5 & -1.11 & 14.7 \\
\hline
\end{tabular}

* Potentially this has a wider bandwidth but is only currently matched to $-5 \mathrm{~dB}$ 


\section{LIST OF FIGURES}

\section{Figure 1. Geometry of the three patch antennas: (a) Circle-shape; (b) LU Shield and (c) bespoke 'Logo'. All distances are in $\mathrm{mm}$}

Figure 2. Simulated reflection coefficient results

Figure 3. Surface currents: (a) Circle-shape at 1.15GHz; (b) Circle-shape at 1.55GHz; (c) LU Shield at 1.06GHz;

(d) LU Shield at $1.88 \mathrm{GHz}$; (e) 'Logo' at $1.14 \mathrm{GHz}$ and (f) 'Logo' at $2.50 \mathrm{GHz}$. Arrows are included to show the current direction

Figure 4. Simulated co-polar radiation patterns for the Circle-shape antenna

Figure 5. Simulated co-polar radiation patterns for the LU Shield Antenna

Figure 6. Simulated co-polar radiation patterns for the 'Logo' antenna

Figure 7. Fabricated antennas: (a) Circle-shape; (b) LU Shield and (c) 'Logo' antenna

Figure 8. The simulated and measured S11 results: (a) the Circle-shape; (b) the LU Shield and (c) 'Logo'

Figure 9. Measured co-polar radiation patterns for the Circle-shape antennaFigure 10. Measured co-polar radiation patterns for the LU Shield antenna

Figure 11. Measured co-polar radiation patterns for the 'Logo' antenna

Figure 12. Comparison between measured and simulated radiation patterns for a) the Circle-shape; (b) the LU Shield and (c) the 'Logo' antenna

Figure 13. 'Logo' antenna shape variants: (a) original design; (b) solid O's; (c) small holes in O's; (d) G connected to 2nd $\mathrm{O}$; (e) slot in first $\mathrm{O}$; (f) slot between first $\mathrm{O}$ and $\mathrm{G}$

Figure 14. Surface currents on 'Logo' variants at the $3 \mathrm{GHz}$ resonance frequency: (a) solid O's; (b) small holes in $\mathrm{O}$ 's; (c) G connected to 2nd O; (d) slot in first $\mathrm{O}$; (e) slot between first $\mathrm{O}$ and $\mathbf{G}$. The arrows indicate the direction 